\title{
Proceeding
}

Supplementary Issue: Autumn Conferences of Sports Science. Costa Blanca Sports Science Events, 18-19 December 2020. Alicante, Spain.

\section{Effects of applying a training program on basketball shooting in young players}

\author{
RICARDO FERRAZ1,2 , MÁRIO C. MARQUES ${ }^{1,2}$, LUÍS BRANQUINHO11, DANIEL A. MARINHO1,2 \\ ${ }^{1}$ Department of Sport Sciences, University of Beira Interior, Covilhã, Portugal \\ ${ }^{2}$ Research Center in Sports Sciences, Health Sciences and Human Development (CIDESD), Portugal
}

\begin{abstract}
The main aim of this study was to determine the effects of the application of a strength program in the accuracy of basketball shooting in young female players. Twenty female basketball players, (mean \pm standard deviation: $12.08 \pm 0.42$ years; $1.55 \pm 0.08$ height; $44.4 \pm 5.54$ body mass) participated in the study. The participants were divided into two groups, the Control Group (GC) and the Experimental Group (GE), and were evaluated in 4 throwing exercises before (Pre-Test), after the application of a 6-week strength program (Post-Test), as well as after 4 weeks of detraining. The applied training program includes four exercises: i) Jump with Counter-Movement; ii) Throwing of the Medicinal Ball; iii) Sit-ups; iv) Push-ups. The results suggest that application of the 6-week training program had a positive effect on performance in two the four throwing exercises. In addiction 4 weeks of detraining, did not cause significant changes in the performance of the different throwing exercises compared to the Post-test period. It was concluded that a strength training program with a duration of 6 weeks was sufficient to obtain positive effects in the effectiveness of 2 Point throwing exercises in young female basketball players.
\end{abstract}

Keywords: Strength training; Throwing ability; Detraining period.

Cite this article as:

Ferraz, R., Marques, M.C., Branquinho, L., \& Marinho, D.A. (2021). Effects of applying a training program on basketball shooting in young players. Journal of Human Sport and Exercise, 16(2proc), S307-S318. doi:https://doi.org/10.14198/ihse.2021.16.Proc2.16

Corresponding author. University of Beira Interior, Department of Sport Sciences. Convento de Santo António, 6201-001 Covilhã, Portugal. https://orcid.org/0000-0002-7530-512X

E-mail: ricardompferraz@gmail.com

Abstract submitted to: Autumn Conferences of Sports Science. Costa Blanca Sports Science Events, 18-19 December 2020. Alicante, Spain.

JOURNAL OF HUMAN SPORT \& EXERCISE ISSN 1988-5202

(c) Faculty of Education. University of Alicante

doi:10.14198/jhse.2021.16.Proc2.16 


\section{INTRODUCTION}

Basketball is characterized as involving intermittent efforts, which requires participants to have excellent levels of physical condition in terms of aerobic and anaerobic capacity (Gantois et al., 2017). It is also characterized by involving successive rapid defence-attack and attack-defence transitions (Gentil et al., 2001). Basketball also provides its practitioners with a wide variety of technical actions, such as throwing, rebounding, passing, dribbling, sprinting, and defensive slips, which contribute to the creation of offensive and defensive actions (Krause and Nelson, 2018). All of these offensive and defensive technical-tactical actions are based on speed, agility, resistance, and flexibility (Ziv and Lidor, 2009) to execute rapid changes of direction and explosive movements (Spiteri et al., 2015). The functional structure of the game is, therefore, directly related to the main physical capacities that determine performance (Oliveira, 2001). Depending on the specific techniques of the game, these physical capacities are enhanced by the factors of strength and speed, and the ability of athletes to resist intermittent effort continued over time.

In the domain of the determining factors for success during a basketball game, motor skills and their level of development appear as fundamental assumptions of performance, ensuring the learning and performance of sports motor actions, as well as the possibility of manifesting high levels of competitive performance (Oslin et al., 1998). From this perspective, coordinative and conditional skills are of particular importance as a basis for motor learning capacity (Wallian and Chang, 2006). While in the coordinating capacities the processes of nerve conduction predominate and depend on sensorimotor aspects, the conditional capacities essentially depend on energetic-functional aspects, where the metabolic processes in the muscles and organic systems predominate (Grosser, 1983). Thus, coordinative capacities include spatial-temporal orientation, motor reaction, coordination, rhythm, and balance. Conditional capabilities include endurance, speed, flexibility, and strength.

The ability to produce strength can be decisive in athletes achieving high levels of performance (Badillo and Ayestarán, 2002). Thus, the development of maximum force is important as a basis for improving power, acceleration, rapid changes of direction, and fast, highly coordinated work. In addition, the development of resistance to force takes on a predominant role, specifically the ability to perform actions repeatedly throughout the game (Robalo, 2009). Strength training is of particular importance for the optimization of strength gains in athletes as it is an essential factor in training for obtaining higher levels of sports performance. In fact, high levels of strength make it possible to increase sports performance and are a basic assumption in the optimization of sporting gestures (Kraemer and Fleck, 2001). This idea is shared by Marques (1993), who states that strength unequivocally integrates the structure of sports performance and manifests itself as a basic requirement for the technical quality of athletes. Thus, previous investigations defend the need to include young basketball players in strength training programs in order to enhance the specific game actions (Kraemer and Fleck, 2005). Marques and González-Badillo (2008) argue that in addition to strengthening and improving physical performance, strength training in young practitioners is crucial to the development of technique and coordination, since often difficulties in improving technique are based on a deficit of strength. Thus, it seems important that young people participate in multifaceted resistance training programs, with strength training being the main process for improving performance and, consequently, optimizing technique (Kraemer and Fleck, 2001).

Bearing in mind that the main goal of basketball is to score a basket, the throw assumes a special preponderance, since it is the culmination of all individual or collective actions performed by the team (Haddad and Tremayne, 2009). Thus, the throw is a specific skill that allows a quick and objective evaluation of performance in basketball, as it is considered one of the variables of differentiating between the value of 
different athletes (Okazaki et al., 2006; Okazaki et al., 2008; Rojas et al., 2000). In addition, previous investigations (Carvalho, 1996) indicated that reduced levels of muscle strength can limit the acquisition and mastery of technical gestures, which can influence the effectiveness of the throw. For this reason, there is also a consensus on the importance of strength training, which has been highlighted in the literature as an increasingly determining factor for success in basketball teams (Padulo et al., 2015; Schelling and TorresRonda, 2016). In fact, a lack of strength training is the main reason for poor throwing performance in young people (Cleary et al., 2006). Deprivation of force, in addition to preventing the ball from reaching the basket, also makes it difficult to carry out the technical gesture correctly, leading to ineffective throws (Cleary et al., 2006). In addition, a previous investigation by Marques and Oliveira (2001) found that the technical errors made by young players are often not due to deficient technique or motor coordination, but rather to a lack of strength in the muscles that are involved in this technical movement.

However, despite the existence of several studies (Ozmen et al., 2014; Santos and Janeira, 2008; Vamvakoudis et al., 2007) on the theme, information is scarce with regard to a specific methodological orientation of training that contributes to better performance. In addition, despite the relevance of strength in basketball and the importance of the throw in the course of the game, the vast majority of the literature only refers to improvements in explosion, sprint, vertical jump, and agility (Erculj et al., 2010; Santos and Janeira, 2008), leaving aside the influence that these aspects have on the technical component of the sport and especially on the throw. Few studies have investigated the influence of force on the effectiveness or performance of technical gestures in basketball, particularly on the pitch. This gap is even more evident in terms of young practitioners. Even so, there are studies about the relationship between physical condition and the percentage of successful throws in professional players during the season (Pojskić et al., 2014), where the results showed a positive relationship between dynamic throwing exercises and players' effectiveness. However, more studies are needed to understand and develop the theme.

Another topic that requires further investigation is the interruption of training sessions, which may be due to several factors, such as illness, injury, vacation, post-season breaks, or other normal factors in any type of sport, resulting in a reduction or interruption of the normal level of physical activity (Kraemer et al., 2002; Marques and González-Badillo, 2006). This phase of reduction or complete cessation of training was previously defined as "detraining" (Mujika and Padilla, 2000). Several studies report that the magnitude of this reduction may depend on the length of the detraining period (Branquinho et al., 2020; Kraemer et al., 2002) in addition to the training levels reached by the subject (Izquierdo et al., 2007). Previous investigations have indicated that three to six weeks of detraining negatively affect aerobic capacity and strength (Izquierdo et al., 2007). In contrast, a period of detraining after applying a training program does not cause a decrease in the performance of basketball players, suggesting that strength training is beneficial for young basketball players (Santos and Janeira, 2011). However, the detraining period and its consequences have not been fully clarified in the literature, especially with regard to young basketball players. To the best of the authors' knowledge, changes in throwing skills due to the impact of detraining as a result of a strength training program, in addition to normal basketball training, have not been investigated, and therefore require further investigation.

Thus, the main objective of this study was to verify whether the application of a strength training program induced improvements in the effectiveness of the throw in young basketball players. In addition, it sought to ascertain whether a detraining period had consequences on the effectiveness of the throw. The study hypothesis was that the strength training program would induce increases in the effectiveness of the throw and that the detraining period would have a reduced impact on the previously acquired gains due to its short duration. 


\section{METHODS}

\section{Subjects}

Twenty female basketball players participated in the study. They were divided into two groups of 10: the Control Group (CG), with a mean age of 12.80 years (standard deviation \pm 0.42 ), a mean weight of $44.4 \mathrm{~kg}$ ( \pm 8.54$)$, a mean height of $1.55 \mathrm{~m}( \pm 0.08)$, and a mean stage of $2.5( \pm 0.52)$ on the Tanner scale; and the Experimental Group (EG), with a mean age of 12.10 years $( \pm 0.56)$, a mean weight of $48.30 \mathrm{~kg}( \pm 9.40)$, a mean height of $1.59 \mathrm{~m}( \pm 0.10)$, and a mean stage of $2.4( \pm 0.51)$ on the Tanner scale (Table 1).

Before the study started, the team physician physically examined all the players, and cleared them of any medical disorders that may have limited full participation in the investigation. All participants and the coach were fully informed verbally and in writing regarding the nature and demands of the study, as well as the known health risks. They completed a health history questionnaire and were informed that they could withdraw from the study at any time, even after giving their written consent. All parents provided their informed consent for the voluntary participation of their children in the study, which had the approval of the Academy's Ethical Advisory Commission and was conducted in accordance with the Declaration of Helsinki.

Table 1. Characteristics of the sample: age, weight, height, and Tanner scale stage (mean \pm standard deviation).

\begin{tabular}{lcccccc}
\hline & $\mathbf{N}$ & Age (years) & Weight $(\mathrm{kg})$ & Height $(\mathrm{m})$ & Tanner (scale) & Years of basketball \\
\hline CG & 10 & $12.80 \pm 0.42$ & $44.4 \pm 8.54$ & $1.55 \pm 0.08$ & $2.5 \pm 0.52$ & $3.9 \pm 1.911$ \\
EG & 10 & $12.10 \pm 0.56$ & $48.30 \pm 9.40$ & $1.59 \pm 0.10$ & $2.4 \pm 0.51$ & $2.5 \pm 1.08$ \\
Total & 20 & $12.45 \pm 0.6$ & $46.35 \pm 8.9$ & $1.57 \pm 0.09$ & $2.45 \pm 0.5$ & $3.2 \pm 1.6$ \\
\hline
\end{tabular}

$C G=$ Control group; $E G=$ Experimental group; $N=$ Sample number .

\section{Experimental design}

The aim of this study was to examine the effects of a six-week training program, which consisted of explosive strength exercises for the upper and lower limbs, on young basketball players' ability to throw. The training program took place over a period of six weeks and was followed by four weeks of detraining. The detraining period allowed us to better understand the impact of the strength training program as a complement to specific technical and tactical training. All players participated in one match and three basketball practice sessions per week. Players completed a pre-season test and training program before the start of this inseason study. The players were in good physical condition and properly familiarized with all procedures before the study started. In addition to standard technical and tactical practice sessions (two hours a day) and regular competitions, participants completed a physical training regime that included lower and upper body exercises for strength and power. All experimental procedures were performed in coordination with the technical team and, therefore, did not change the players' routine. All tests were carried out for one week at the end of the second half of the season, which took place between January and April. Before the pre-test phase, participants were familiarized with the different tests during the practice session, in order to minimize the effects of learning.

The entire sample was evaluated during four throwing exercises before (pre-test) and after (post-test) the application of a six-week strength training program, as well as after four weeks of detraining. The exercises were chosen according to the protocol used by Pojskić et al. (2014), with the following releases: i) free throw; ii) stationary two-point shooting test; iii) dynamic 60 -second two-point shooting test; and iv) stationary threepoint shooting test. In the throwing exercises all participants performed three series of 10 throws and the number of achievements (effectiveness) in all series was recorded, using the average of the 10 throws. After 
performing the pre-test, the EG performed a bi-weekly protocol for six weeks. The protocol included four exercises: i) counter-movement jump (CMJ); ii) throwing a medicine ball; iii) sit-ups; and iv) push-ups. After the six weeks in which the EG protocol was performed, throwing tests were repeated for both groups and their effectiveness was recorded again. The effectiveness of the throwing after a detraining period with a duration of four weeks ( 10 weeks after the application of the pre-test) was also analysed.

\section{Training program}

The program was performed twice a week, with each session lasting approximately 20 minutes. The program was performed right after warm-up to ensure that players were in a state of rest and obtained the best benefits from the specific strength training program. The training program was applied for six weeks and consisted of CMJ, a $2 \mathrm{~kg}$ medicine ball throw (TMB), sit-ups, and push-ups, as described in Table 2.

Table 2. Strength training program.

\begin{tabular}{lcccccc}
\hline & Week 1 & Week 2 & Week 3 & Week 4 & Week 5 & Week 6 \\
\hline Exercises & Session 1¥ & Session 3¥ & Session $5^{*}$ & Session $7^{*}$ & Session $9^{*}$ & Session $11^{*}$ \\
\hline CMJ & $2 \times 4$ & $3 \times 4$ & $3 \times 4$ & $4 \times 8$ & $4 \times 8$ & $6 \times 10$ \\
TMB & $2 \times 4$ & $3 \times 4$ & $3 \times 4$ & $3 \times 5$ & $4 \times 4$ & $4 \times 5$ \\
Sit-ups & $1 \times 60 \mathrm{~s}$ & $1 \times 60 \mathrm{~s}$ & $1 \times 60 \mathrm{~s}$ & $1 \times 60 \mathrm{~s}$ & $2 \times 60 \mathrm{~s}$ & $2 \times 60 \mathrm{~s}$ \\
Push-ups & $1 \times 60 \mathrm{~s}$ & $1 \times 60 \mathrm{~s}$ & $1 \times 60 \mathrm{~s}$ & $1 \times 60 \mathrm{~s}$ & $2 \times 60 \mathrm{~s}$ & $2 \times 60 \mathrm{~s}$ \\
\hline Exercises & Session $2^{¥}$ & Session $4^{*}$ & Session $6^{*}$ & Session $8^{*}$ & Session $10^{*}$ & Session $12^{*}$ \\
\hline CMJ & $2 \times 4$ & $3 \times 4$ & $4 \times 4$ & $4 \times 8$ & $5 \times 8$ & $6 \times 10$ \\
TMB & $2 \times 4$ & $3 \times 4$ & $3 \times 5$ & $4 \times 5$ & $4 \times 4$ & $4 \times 5$ \\
Sit-ups & $1 \times 60 \mathrm{~s}$ & $1 \times 60 \mathrm{~s}$ & $1 \times 60 \mathrm{~s}$ & $1 \times 60 \mathrm{~s}$ & $2 \times 60 \mathrm{~s}$ & $2 \times 60 \mathrm{~s}$ \\
Push-ups & $1 \times 60 \mathrm{~s}$ & $1 \times 60 \mathrm{~s}$ & $1 \times 60 \mathrm{~s}$ & $1 \times 60 \mathrm{~s}$ & $2 \times 60 \mathrm{~s}$ & $2 \times 60 \mathrm{~s}$ \\
\hline
\end{tabular}

Note: $¥=2$ minutes of recovery between sets and 3 minutes between exercises; ${ }^{*}=1$ minute of recovery between sets and 2 minutes between exercises; $C M J=$ counter movement jump; $T M B=$ throwing a medicine ball.

\section{Statistical analysis}

Descriptive analysis was performed using means and standard deviations. (Batterham and Hopkins, 2006). The comparison between the different moments (pre, post, and detraining) of both groups (experimental and control) were inferred through standardized mean differences computed with pooled variance and respective 90\% confidence intervals (Batterham and Hopkins, 2006; Cumming, 2012). The limits for statistics were set at: trivial [0.2]; small [0.6]; moderate [1.2]; large [2.0], and very large [>2.0] according to the method described by Hopkins et al. (2009). The smallest valuable differences were estimated from standard units multiplied by 0.2 . Probabilities were used to make a qualitative probabilistic mechanistic inference about the true effect (i.e., if the probabilities of the effect being substantially higher and lower were both $>5 \%$, the effect was reported as unclear; if not, the effect was clear and reported as the magnitude of the observed value). The scale was: possible [25-75\%]; likely [75-95\%]very likely [95-99\%]; most likely >99\% (Hopkins et al., 2009).

\section{RESULTS}

Table 3 and Figure $1(a, b, c)$ show the effects when comparing the three moments of analysis (pre-training, post-training, and detraining) between the CG and EG. 
Table 3. Comparison between the three moments analysed.

\begin{tabular}{|c|c|c|c|c|c|c|c|c|c|}
\hline & CG & & & EG & & & \multirow{2}{*}{\multicolumn{3}{|c|}{$\begin{array}{l}\text { Difference in means ( } \pm 90 \% \mathrm{CL}) \text {, } \\
\text { uncertainty in the values found, and } \\
\text { non-clinical inferences based on } \\
\text { magnitude }\end{array}$}} \\
\hline \multirow[t]{2}{*}{ Variables } & \multirow[t]{2}{*}{$\begin{array}{l}\text { Pre- } \\
\text { Training }\end{array}$} & \multirow[t]{2}{*}{$\begin{array}{l}\text { Post- } \\
\text { Training }\end{array}$} & \multirow[t]{2}{*}{ Detraining } & \multirow[t]{2}{*}{$\begin{array}{l}\text { Pre- } \\
\text { Training }\end{array}$} & \multirow[t]{2}{*}{$\begin{array}{l}\text { Post- } \\
\text { Training }\end{array}$} & \multirow[t]{2}{*}{ Detraining } & & & \\
\hline & & & & & & & $a$ & b & $\mathrm{c}$ \\
\hline $\begin{array}{l}\text { Free } \\
\text { Throw }\end{array}$ & $4.4 \pm 1.46$ & $4.27 \pm 2.00$ & $5.07 \pm 1.66$ & $3.70 \pm 2.21$ & $3.40 \pm 1.25$ & $3.90 \pm 1.97$ & $\begin{array}{c}-0.2 ; \pm 1.3 \\
\text { unclear }\end{array}$ & $\begin{array}{c}-0.5 ; \pm 1.1 \\
\text { unclear }\end{array}$ & $\begin{array}{c}-0.3 ; \pm 1.1 \\
\text { unclear }\end{array}$ \\
\hline $\begin{array}{l}\text { S2Points } \\
\text { Shot }\end{array}$ & $3.10 \pm 1.66$ & $2.90 \pm 1.63$ & $4.13 \pm 1.69$ & $2.40 \pm 1.46$ & $2.77 \pm 1.68$ & $3.80 \pm 1.38$ & $\begin{array}{l}0.6 ; \pm 0.7 \\
\text { Possible } \\
\text { +ive }\end{array}$ & $\begin{array}{l}0.4 ; \pm 0.8 \\
\text { unclear }\end{array}$ & $\begin{array}{c}-0.2 ; \pm 0.9 \\
\text { unclear }\end{array}$ \\
\hline $\begin{array}{l}\text { D2Points } \\
\text { Shot }\end{array}$ & $2.80 \pm 1.63$ & $2.90 \pm 1.88$ & $3.43 \pm 1.55$ & $1.93 \pm 1.16$ & $2.97 \pm 1.13$ & $3.87 \pm 1.62$ & $\begin{array}{c}0.9 ; \pm 0.5 \\
\text { most likely } \\
\text { +ive }\end{array}$ & $\begin{array}{l}1.3 ; \pm 0.8 \\
\text { very likely } \\
\quad \text { +ive }\end{array}$ & $\begin{array}{c}0.4 ; \pm 0.9 \\
\text { unclear }\end{array}$ \\
\hline $\begin{array}{l}\text { S3Ppoints } \\
\text { Shot }\end{array}$ & $1.80 \pm 1.58$ & $1.77 \pm 1.52$ & $2.27 \pm 1.48$ & $0.70 \pm 1.22$ & $1.00 \pm 1.36$ & $1.17 \pm 1.39$ & $\begin{array}{l}0.3 ; \pm 0.7 \\
\text { unclear }\end{array}$ & $\begin{array}{l}0.0 ; \pm 0.8 \\
\text { unclear }\end{array}$ & $\begin{array}{c}-0.3 ; \pm 0.8 \\
\text { unclear }\end{array}$ \\
\hline
\end{tabular}

Note: +ive = positive; $C L$ = confidence limits. Difference in means (absolute values) are identified as: a) pre-training vs. posttraining; b) pre-training vs. detraining; c) post-training vs. detraining; S2Points Shot = stationary two-point shooting test; D2Points Shot = dynamic 60-second two-point shooting test; S3Points Shot = stationary three-point shooting test.
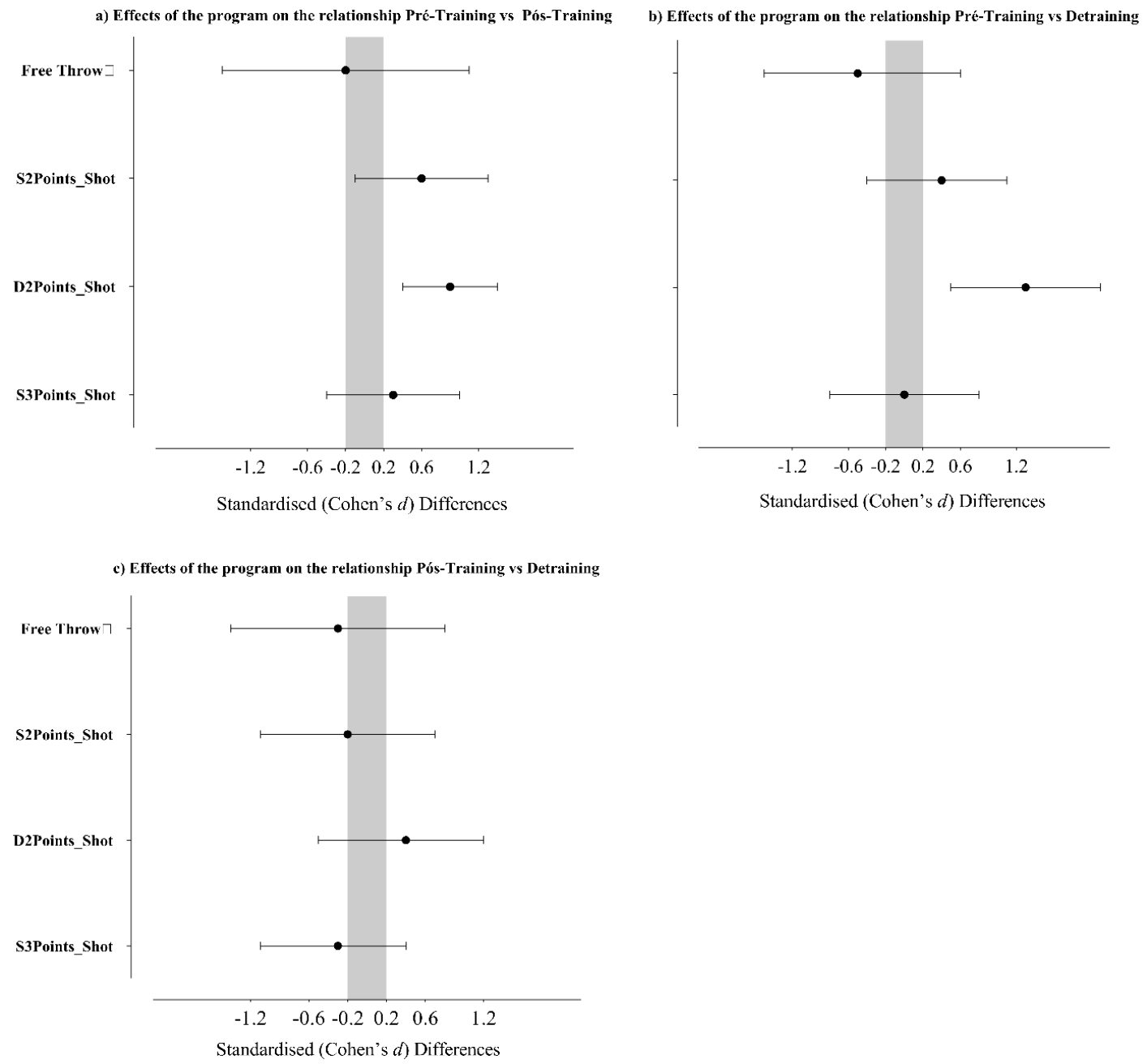

Figure 1. Results of the comparison of the effects of the training program on the relationship between: a) pretraining vs post-training; b) pre-training vs detraining; and c) post-training vs detraining. 
Comparing the pre-training with the post-training, the effects of the strength training program had a positive impact on two of the four variables analysed (stationary two-point shooting test and dynamic 60-second twopoint shooting test) with a possible increase (difference in means; $90 \% \mathrm{CL}-0.6 ; \pm 0.7$ ) in the variable stationary two-point shooting test and a very likely increase $(0.9 ; \pm 0.5)$ in the variable dynamic 60 -second two-point shooting test, with a moderate effect in both.

Comparing the pre-training and detraining moments, the performance for the variables free throw, variable stationary two-point shooting test, and stationary three-point shooting test tended to be similar with an unclear effect $(-0.5 ; \pm 1.1 ; 0.4 ; \pm 0.8 ; 0.0 ; \pm 0.8)$. In the dynamic 60 -second two-point shooting test variable, the performance was superior at the time of detraining (very likely: $1.3 ; \pm 0.8$ ), with a large positive effect.

In the comparison between the post-training and detraining moments, the differences were unclear in terms of the four throws analysed (unclear effect) and the results tended to be similar in all the variables analysed.

\section{DISCUSSION}

This study aimed to evaluate the effect of a six-week strength training program on female U-14 basketball players' throwing effectiveness. In addition, an attempt was made to investigate the effect of a four-week detraining period on throwing effectiveness. The most important results of this work suggest that the application of the six-week strength training program had a positive effect on the performance of two types of throws (stationary two-point shooting test and dynamic 60-second two-point shooting test). In addition, the detraining period (four weeks) did not cause significant changes in the performance of the different throws compared to the post-training period.

The results regarding the increase in performance of the stationary two-point shooting test and dynamic 60second two-point shooting test are in line with previous investigations (Faigenbaum, 2000; Faigenbaum et al., 2009; Kraemer et al., 1989; Marques and González-Badillo, 2008) that support the importance of strength training in increasing the strength levels of children and young people, which is reflected in their performance. Strength has gained importance in the training of young people and has contributed to higher quality specialized training (Marques and Oliveira, 2001).

It is known that the initial growth of strength is closely linked to neural adaptations (Folland and Williams, 2007). These developments occur in the first weeks of training (Badillo and Ayestarán, 2002), especially in untrained or inexperienced individuals (Fleck, 1999). Thus, the manifestation of strength in the two variables mentioned will be correlated not only to muscle mass, but also to the development of the activation potential of the nervous system (Folland and Williams, 2007; Sale, 1988).

Regarding the stationary three-point shooting test, the non-increase in performance may be due to the fact that, although strength gains have been obtained, these are not enough for athletes to improve this type of throw. This may indicate that the strength training program implemented had a short period of time in which to achieve positive results in this variable. In addition, in young players, there is a clear preference for twopoint throws in a basketball game (Arias et al., 2009; Mexas et al., 2005). Coaches prioritize two-point throws, which take place closer to the basket (Mexas et al., 2005). Thus, young players have a lower propensity to make a three-point throw in training or in a game, which may also have influenced the final results. In the future, it would be important to evaluate this variable by applying a strength training program with a longer duration. 
The effects of the training program were not felt in the free throw. Kozar et al. (1994), assuming the importance of the free throw during a formal game of basketball, carried out a study using as a sample basketball games between male university students. The results confirmed the authors' theory, indicating that the teams that successfully made a greater percentage of free throws were the winners of the most balanced and decisive games. Several authors (Foster et al., 2006; Lonsdale and Tam, 2008) consider that the free throw is influenced by several factors of a psychological nature. Likewise, previous investigations state that the effectiveness of the free throw depends on several factors, among which are the throwing mechanics, the relaxation capacity, the concentration capacity, and the quantity and quality of training (Gooding and Gardner, 2009). In this sense, we can infer that the non-improvement of the free throw in the present study may be associated with several factors that condition and limit this type of throw and that should be taken into account together with the potential positive effects of strength training.

Comparing the pre-training and detraining moments, there was a trend towards approximating the pretraining values of all variables except the dynamic 60 -second two-point shooting test (Figure 1), suggesting that the prolongation of the detraining time could lead to the confirmation of this trend. In fact, according to the literature, at the end of a strength training program, a decrease or stagnation in players' performance is expected (Faigenbaum, 2000; Fleck, 1999; Kraemer et al., 2002). Faigenbaum (2000) corroborates this idea, stating that the strength gains in pre-adolescents are not permanent during detraining and tend to return to pre-training values. Marques et al. (2006) confirm that the magnitude of the reduction in performance or losses resulting from the absence of strength training always depend on the duration of detraining and the level of training achieved by the athlete. In this sense, in the present study, the four weeks of detraining seem to have led to a loss of strength capacity that was reflected in the different variables. In this context, the association between strength and the effectiveness of the stationary three-point shooting test emphasizes the importance of maintaining strength training in permanently improving and developing technical skills. In the future it would be important to study and develop this topic that seems to be innovative given the scarcity of studies in the literature.

In relation to the dynamic 60-second two-point shooting test, the performance was superior at the time of detraining; therefore, the four weeks of detraining did not lead to a loss of performance in this variable, although the graphic analysis suggests some weighting due to the increase in individual variation in this period (Figure 1). A study conducted by Pojskić et al. (2014) on the relationship between physical condition and the effectiveness of throws during a season concluded that players who obtain better results in dynamic exercises achieve better percentages of throws during the sports season. These justification for these results was that these exercises reflect what happens during the games. In effect, the variable dynamic 60 -second two-point shooting test in the present study was realized through a dynamic exercise performed quickly after passing, and therefore functionally very close to the functional dynamics of the throw during a basketball game. In this sense, it is likely that throughout the study period the frequency (i.e., number of repetitions) of this gesture was much higher than that of the other variables, leading to an improvement that the detraining period did not condition. In addition to strength training, which seems to be decisive in improving technique (Marques and Oliveira, 2001; Matavulj et al., 2001), we cannot ignore the improvements associated with the mechanical and coordinated execution of the technical gesture at high frequencies of achievement. Thus, and according to several authors (Marques and Oliveira, 2001; Santos and Janeira, 2011), basketball training may be sufficient to maintain levels of performance previously obtained for some weeks and after the interruption of strength training, due to the demands that this modality presents.

In the comparison between the post-training and detraining moments, it is important to emphasize that the data obtained do not present significant changes in the four analysed throws (unclear effect), and the results 
tended to be similar in all the analysed variables. This may indicate that the four weeks of detraining may not have been enough to cause a loss of capacity in the variables.

\section{CONCLUSION}

The results of this study suggest that the application of a strength training program with a duration of six weeks is sufficient to obtain positive effects in relation to the effectiveness of two-point launching exercises in female basketball players at the under-14 level. The strength training program that was implemented also seems to favour the effectiveness of the launch exercises that correspond more to real game situations and are used more in the competitions at this level. The results related to detraining, despite the tendency to approach pre-training values, do not show significant changes in the effectiveness of the evaluated launches, suggesting that four weeks of detraining may not be a sufficient period of time for significant losses to occur in relation to previously acquired gains. This study reinforces the importance of strength training in the context of training in the basketball modality and specifically in technical performance. Therefore, strength training for young basketball classes during the sporting season should be carefully planned to improve the technical component and consequently the effectiveness of the launch.

\section{ACKNOWLEDGMENTS}

This work is supported by national funding through the Portuguese Foundation for Science and Technology, I.P., under project UID04045/2020.

\section{REFERENCES}

Arias, J. L., Argudo, F. M., \& Alonso, J. I. (2009). Effect of the 3-point line change on the game dynamics in girls' minibasketball. Res. Q. Exerc. Sport. https://doi.org/10.1080/02701367.2009.10599588

Badillo, J. J. G., \& Ayestarán, E. G. (2002). Fundamentos del entrenamiento de la fuerza. Aplicación al alto rendimiento deportivo: texto básico del Máster Universitario en Alto Rendimiento Deportivo del Comité Olímpico Español y de la Universidad Autónoma de Madrid. Inde.

Batterham, A. M., \& Hopkins, W. G. (2006). Making meaningful inferences about magnitudes. Int. J. Sports Physiol. Perform., 1(1), 50-57. https://doi.org/10.1123/ijspp.1.1.50

Branquinho, L., Ferraz, R., Mendes, P. D., Petricia, J., Serrano, J., \& Marques, M. C. (2020). The effect of an in-season 8-week plyometric training programme followed by a detraining period on explosive skills in competitive junior soccer players. Montenegrin J. Sport. Sci. Med., 9(1). https://doi.org/10.26773/mjssm.200305

Carvalho, C. (1996). A força em crianças e jovens. O seu desenvolvimento e treinabilidade.

Cleary, T. J., Zimmerman, B. J., \& Keating, T. (2006). Training physical education students to selfregulate during basketball free throw practice. Res. Q. Exerc. Sport, 77(2), 251-262. https://doi.org/10.1080/02701367.2006.10599358

Cumming, G. (2012). Understanding the new statistics: Effect sizes, confidence intervals, and metaanalysis. Routledge. https://doi.org/10.4324/9780203807002

Erculj, F., Blas, M., \& Bracic, M. (2010). Physical demands on young elite European female basketball players with special reference to speed, agility, explosive strength, and take-off power. J. Strength Cond. Res., 24(11), 2970-2978. https://doi.org/10.1519/JSC.0b013e3181e38107

Faigenbaum, A. D. (2000). Strength training for children and adolescents. Clin. Sports Med., 19(4), 593619. https://doi.org/10.1016/S0278-5919(05)70228-3 
Faigenbaum, A. D., Kraemer, W. J., Blimkie, C. J. R., Jeffreys, I., Micheli, L. J., Nitka, M., \& Rowland, T. W. (2009). Youth resistance training: updated position statement paper from the national strength and conditioning association. J. Strength Cond. Res., 23, S60-S79. https://doi.org/10.1519/JSC.0b013e31819df407

Fleck, S. J. (1999). Periodized Strength Training: A Critical Review. In Journal of Strength and Conditioning Research (Vol. 13, Issue 1). https://doi.org/10.1519/15334287(1999)013<0082:PSTACR>2.0.C0;2

Folland, J. P., \& Williams, A. G. (2007). The adaptations to strength training: Morphological and neurological contributions to increased strength. Sport. Med., 37(2), 145-168. https://doi.org/10.2165/00007256-200737020-00004

Foster, D. J., Weigand, D. A., \& Baines, D. (2006). The effect of removing superstitious behavior and introducing a pre-performance routine on basketball free-throw performance. J. Appl. Sport Psychol. https://doi.org/10.1080/10413200500471343

Gantois, P., Aidar, F. J., De Matos, D. G., De Souza, R. F., Da Silva, L. M., De Castro, K. R., De Medeiros, R. C. S. C., \& Cabral, B. G. A. T. (2017). Repeated sprints and the relationship with anaerobic and aerobic fitness of basketball athletes. J. Phys. Educ. Sport, 17(2), 910.

Gentil, D. A. S., Oliveira, C. P. S., Barros Neto, T. L., \& Tambeiro, V. L. (2001). Avaliação da seleção brasileira feminina de basquete. Rev. Bras. Med. Do Esporte, 7(2), 53-56. https://doi.org/10.1590/s1517-86922001000200002

Gooding, A., \& Gardner, F. L. (2009). An investigation of the relationship between mindfulness, preshot routine, and basketball free throw percentage. J. Clin. Sport Psychol. https://doi.org/10.1123/jcsp.3.4.303

Grosser, M. (1983). Capacidades motoras. Treino Desport., 23, 23-32.

Haddad, K., \& Tremayne, P. (2009). The effects of centering on the free-throw shooting performance of young athletes. Sport Psychol., 23(1), 118-136. https://doi.org/10.1123/tsp.23.1.118

Hopkins, W. G., Marshall, S. W., Batterham, A. M., \& Hanin, J. (2009). Progressive statistics for studies in sports medicine and exercise science. Med. Sci. Sports Exerc., 41(1), 3-12. https://doi.org/10.1249/MSS.0b013e31818cb278

Izquierdo, M., Martínez, J. I., Badillo, J. J. G., Ratamess, N. A., Kraemer, W. J., Häkkinen, K., Bonnabau, H., Domínguez, C. G., French, D. N., \& Ayestarán, E. G. (2007). Detraining and Tapering Effects on Hormonal Responses and Strength Performance. J. Strength Cond. Res. Res. J. NSCA, 21(3), 768775. https://doi.org/10.1519/R-21136.1

Kozar, B., Vaughn, R. E., Whitfield, K. E., Lord, R. H., \& Dye, B. (1994). Importance of Free-Throws at Various Stages of Basketball Games. Percept. Mot. Skills. https://doi.org/10.2466/pms.1994.78.1.243

Kraemer, W.J. \& Fleck, S. J. (2001). Treinamento de Força Para Jovens Atletas. Manole.

Kraemer, W. J., Fry, A. C., Frykman, P. N., Conroy, B., \& Hoffman, J. (1989). Resistance training and youth. Pediatr. Exerc. Sci., 1(4), 336-350. https://doi.org/10.1123/pes.1.4.336

Kraemer, W. J., Koziris, L. P., Ratamess, N. A., Häkkinen, K., Triplett-McBride, N. T., Fry, A. C., Gordon, S. E., Volek, J. S., French, D. N., Rubin, M. R., Gómez, A. L., Sharman, M. J., Lynch, J. M., Izquierdo, M., Newton, R. U., \& Fleck, S. J. (2002). Detraining produces minimal changes in physical performance and hormonal variables in recreationally strength-trained men. J. Strength Cond. Res., 16(3), 373-382. https://doi.org/10.1519/1533-4287(2002)016<0373:DPMCIP>2.0.CO;2

Krause, J. V, \& Nelson, C. (2018). Basketball skills \& drills. Human Kinetics.

Lonsdale, C., \& Tam, J. T. M. (2008). On the temporal and behavioural consistency of pre-performance routines: An intra-individual analysis of elite basketball players' free throw shooting accuracy. J. Sports Sci. https://doi.org/10.1080/02640410701473962 
Marques, A. (1993). Treino da força: Consequências para a saúde da criança. Rev. Horiz., 10(55), 7-11. Marques, A. T., \& Oliveira, J. M. (2001). 0 treino dos jovens desportistas. Actualização de alguns temas que fazem a agenda do debate sobre a preparação dos mais jovens. Rev. Port. Ciências Do Desporto, 2001(1), 130-137. https://doi.org/10.5628/rpcd.01.01.130

Marques, M. A. C., \& González-Badillo, J. J. (2008). 0 efeito do treino de força sobre o salto vertical em jogadores de 10-13 anos de idade. Rev. Bras. Ciência e Mov., 13(2), 93-100. https://doi.org/10.18511/rbcm.v13i2.630

Marques, M. C., \& González-Badillo, J. J. (2006). In-season resistance training and detraining in professional team handball players. J. Strength Cond. Res., 20(3), 563-571. https://doi.org/10.1519/R-17365.1

Matavulj, D., Kukolj, M., Ugarkovic, D., Tihanyi, J., \& Jaric, S. (2001). Effects of plyometric training on jumping performance in junior basketball players. J. Sports Med. Phys. Fitness, 41(2), 159-164.

Mexas, K., Tsitskaris, G., Kyriakou, D., \& Garefis, A. (2005). Comparison of effectiveness of organized offences between two different championships in high level basketball. Int. J. Perform. Anal. Sport. https://doi.org/10.1080/24748668.2005.11868317

Mujika, I., \& Padilla, S. (2000). Detraining: loss of training-induced physiological and performance adaptations. Part I. Sport. Med., 30(2), 79-87. https://doi.org/10.2165/00007256-200030020-00002

Okazaki, V H A, Oliveira, G. O., Ferreira Júnior, R., \& Rodacki, A. L. F. (2006). Coordenação do arremesso jump no basquetebol de crianças. Fédération Int. D'éducation Phys., 76(2), 523-526.

Okazaki, Victor H A, Rodacki, A. L. F., Sarraf, T. A., Dezan, V. H., \& Okazaki, F. H. A. (2008). Diagnóstico de especificidade técnica dos jogadores de basquetebol. Rev. Bras. Ciência e Mov., 12(4), 19-24.

Oliveira, J. (2001). A capacidade de resistência em basquetebol. Tendências Atuais Da Investig. Em Basqu., 241.

Oslin, J. L., Mitchell, S. A., \& Griffin, L. L. (1998). The Game Performance Assessment Instrument (GPAl): Development and preliminary validation. J. Teach. Phys. Educ., 17(2), 231-243. https://doi.org/10.1123/itpe.17.2.231

Ozmen, T., Yuktasir, B., Yildirim, N. U., Yalcin, B., \& Willems, M. E. T. (2014). Explosive strength training improves speed and agility in wheelchair basketball athletes. Rev. Bras. Med. Do Esporte, 20(2), 97100. https://doi.org/10.1590/1517-86922014200201568

Padulo, J., Attene, G., Migliaccio, G. M., Cuzzolin, F., Vando, S., \& Ardigò, L. P. (2015). Metabolic optimisation of the basketball free throw. J. Sports Sci., 33(14), 1454-1458. https://doi.org/10.1080/02640414.2014.990494

Pojskić, H., Šeparović, V., Muratović, M., \& Uièanin, E. (2014). The relationship between physical fitness and shooting accuracy of professional basketball players. Motriz. Rev. Educ. Fis., 20(4), 408-417. https://doi.org/10.1590/S1980-65742014000400007

Rojas, F. J., Cepero, M., Oña, A., \& Gutierrez, M. (2000). Kinematic adjustments in the basketball jump shot against an opponent. Ergonomics, 43(10), 1651-1660. https://doi.org/10.1080/001401300750004069

Sale, D. G. (1988). Neural adaptation to resistance training. Med. Sci. Sports Exerc., 20(5), S135-S145. https://doi.org/10.1249/00005768-198810001-00009

Santos, E. J. A. M., \& Janeira, M. A. A. S. (2008). Effects of complex training on explosive strength in adolescent male basketball players. J. Strength Cond. Res., 22(3), 903-909. https://doi.org/10.1519/JSC.0b013e31816a59f2

Santos, E. J. A. M., \& Janeira, M. A. A. S. (2011). The effects of plyometric training followed by detraining and reduced training periods on explosive strength in adolescent male basketball players. J. Strength Cond. Res., 25(2), 441-452. https://doi.org/10.1519/JSC.0b013e3181b62be3 
Schelling, X., \& Torres-Ronda, L. (2016). An integrative approach to strength and neuromuscular power $\begin{array}{llll}\text { training for basketball. Strength } & \text { Cond. J., 38(3), }\end{array}$ https://doi.org/10.1519/SSC.0000000000000219

Spiteri, T., Newton, R. U., Binetti, M., Hart, N. H., Sheppard, J. M., \& Nimphius, S. (2015). Mechanical determinants of faster change of direction and agility performance in female basketball athletes. J. Strength Cond. Res., 29(8), 2205-2214. https://doi.org/10.1519/JSC.0000000000000876

Vamvakoudis, E., Vrabas, I. S., Galazoulas, C., Stefanidis, P., Metaxas, T. I., \& Mandroukas, K. (2007). Effects of basketball training on maximal oxygen uptake, muscle strength, and joint mobility in young basketball players. J. Strength Cond. Res., 21(3), 930. https://doi.org/10.1519/R-18435.1

Wallian, N., \& Chang, C. W. (2006). 3.7 Development and learning of motor skill competencies. Handb. Phys. Educ., 292. https://doi.org/10.4135/9781848608009.n17

Ziv, G., \& Lidor, R. (2009). Physical attributes, physiological characteristics, on-court performances and nutritional strategies of female and male basketball players. Sport. Med., 39(7), 547-568. https://doi.org/10.2165/00007256-200939070-00003

\section{(9) $\odot \Theta \Theta$}

This work is licensed under a Attribution-NonCommercial-NoDerivatives 4.0 International (CC BY-NC-ND 4.0). 